\title{
Factors Affecting the Result of Intralesional Corticosteroid Injection in Patients With Oral Lichen Planus
}

\author{
Young Chan Lee ${ }^{1,2} \cdot$ Jun Seok Lee ${ }^{1} \cdot$ Ah Ra Jung ${ }^{2} \cdot$ Jung Min Park$^{1} \cdot$ Young-Gyu Eun ${ }^{1,2}$ \\ ${ }^{1}$ Department of Otolaryngology-Head and Neck Surgery, Kyung Hee University Medical Center, Seoul; \\ ${ }^{2}$ Department of Otolaryngology-Head and Neck Surgery, Kyung Hee University Graduate School, Seoul, Korea
}

Objectives. To examine the factors which affect the improvement or the recurrence of disease after intralesional steroid injection in patients with oral lichen planus (OLP).

Methods. Sixty-two patients diagnosed as OLP were treated with intralesion corticosteroid injection. To evaluate the objective severity of OLP, total severity score of OLP was assessed. To examine the factors affecting the therapeutic effect of intralesional steroid injection, factors were compared between the symptom-improved group and symptom-notimproved group. To assess the symptom of patients, patients filled in 10-cm visual analogue scale, along with an Oral Health Impact Profile-14.

Results. Symptoms improved in 50 patients (80.6\%, symptom-improved group), but not in 12 patients (symptom-not-improved group). In a comparison between both group, OLP with lip involvement was the only variable which showed significant difference $(P=0.008)$. Twenty-nine of 50 patients had recurrence of OLP ( $58 \%$, recurrence group) and 21 of 50 patients did not have recurrence ( $42 \%$, no-recurrence group). Statistically significant differences were not found between both groups.

Conclusion. This study suggested that patients suffering from OLP with lesion on the lip might not be effective in treating with intralesional corticosteroid injection.

Keywords. Oral Lichen Planus; Corticosteroid; Treatment

\section{INTRODUCTION}

Oral lichen planus (OLP) is a common chronic inflammatory mucocutaneous disease that typically affects the oral mucosa and causes noninfectious ulceration though the precise etiology of OLP is unknown [1-6]. The tendency towards an increased incidence of OLP has recently been shown to increase for reasons such as psychological stress [4,7]. Additionally, it is also be-

\footnotetext{
- Received September 28, 2017

Revised December 6, 2017

Accepted December 30, 2017

- Corresponding author: Young-Gyu Eun

Department of Otolaryngology-Head and Neck Surgery, Kyung Hee

University Medical Center, 23 Kyungheedae-ro, Dongdaemun-gu, Seoul 02447, Korea

Tel: +82-2-958-8474, Fax: +82-2-958-8470

E-mail: ygeun@hanmail.net
}

ing reported that OLP is occurring at a higher rate in postmenopausal women and post-middle-aged men [4]. Also, it is well known that OLP is associated with other medical conditions such as chronic liver disease and oral cavity cancer [4]. Current data suggest that OLP is a T cell-mediated autoimmune disease in which auto-cytotoxic CD8+ T cells trigger apoptosis of oral epithelial cells $[8,9]$. Therefore, the most common treatment option of OLP is management of the condition with topical or systemic corticosteroids in OLP patients $[10,11]$ although chemotherapy with retinoic acid, cyclosporine, and photochemotherapy [12] is used today. Topical corticosteroids have been considered to be the first-choice agent for the treatment of OLP [7]. In a comparison study between intralesional injection of triamcinolone acetonide (TA) versus a TA mouth rinse, the efficacies of both treatment were found to be similar, but intralesional injection of TA had a lower adverse effect [13].

Copyright $\odot 2018$ by Korean Society of Otorhinolaryngology-Head and Neck Surgery.

This is an open-access article distributed under the terms of the Creative Commons Attribution Non-Commercial License (http://creativecommons.org/licenses/by-nc/4.0)

which permits unrestricted non-commercial use, distribution, and reproduction in any medium, provided the original work is properly cited. 
It is still not known which patient respond well to local corticosteroid treatment. Also, it is not known which patients will relapse after topical corticosteroid treatment. The aims of this study were to examine the factors affecting the therapeutic effect of intralesional corticosteroid injection and to determine the factors affecting recurrence after treatment in patients with OLP.

\section{MATERIALS AND METHODS}

\section{Patients}

This study was a prospective cohort study involving patients with OLP. The study was performed at two university hospitals. Patients who had been diagnosed with OLP by means of clinical and histopathologic examination were enrolled. The exclusion criteria were as follows: potential candidates for the study were excluded if they were under 18 years old; had a history of topical or systemic corticosteroid usage for treating OLP in the past 4 weeks; had a history of using medications capable of inducing lichenoid reactions; had a history of taking the immunosuppressive medication; had a history of corticosteroid allergy; had oral cavity malignancy; were experiencing pregnancy and lactation; or were unwilling to attend the study. All of the enrolled patients in this study had an intralesional injection of TA $(40 \mathrm{mg} / \mathrm{mL}$; Hanall Biopharma, Seoul, Korea). Intralesional TA injection was carried out once a week for 4-6 weeks. The injection was placed directly into the subepithelial tissue just underlying the lesion adjacent to the normal mucosa. Intralesional injections of TA were conducted by two otolaryngologists. Written informed consents were obtained. This study was approved by Institutional Review Boards (IRB No. KHNMC 2015-08-020-005 \& KMC IRB 1303-05).

\section{Measurement}

To assess the pain of the OLP patients, patients filled out a 10$\mathrm{cm}$ visual analogue scale (VAS) at each time they visited the hospital. In particular, the category of VAS was divided into oral pain and burning mouth sensation; then the sum of VAS subcategories was measured (range, 0 to 20 points). Also, quality of life of patients with OLP was evaluated with Oral Health Impact

\section{H I G H L I G H T S}

- This study was to investigate the factors which affect the improvement or the recurrence of disease after intralesional steroid injection for oral lichen planus (OLP).

- Symptoms improved in 50 patients after treatment, but not in 12 patients.

- Patients with lip lesion of OLP might not be effective in treating with intralesional corticosteroid injection.
Profile-14 (OHIP-14) [14] in every hospital visit. The OHIP-14 is a self-administered questionnaire that evaluates quality of life using 14 items to measure seven dimensions: functional limitation, physical pain, psychological discomfort, physical disability, psychological disability, social disability, and handicap. Each dimension is measured by two questions. Subjects were asked how often they had had negative impacts in these dimensions. Responses to the questions were recorded using a 5-point Likert scale: 0 , never; 1 , hardly ever; 2 , occasionally; 3 , fairly often; and 4 , very often. The overall score for the OHIP-14 was achieved by summing all responses (range, 0 to 56 points).

Signs of OLP were quantified using a special scoring system for OLP by Escudier et al. [15]. The extent of the lesion and disease severity at each site was measured and scored. The oral cavity was divided into 17 sites, and criterion-based numerical scores for each site were given. Variables assessed were the extent of site involvement (site score: range, 0 to 2 points) and the severity of the lesion at each site (activity score: range, 0 to 3 points). The activity of the disease was indicated as being the site score multiplied by the severity score. Additionally, the pain score was included. Pain was self-evaluated by the patient on a scale of 0 to 10 over only the previous 2 weeks. Through this special scoring system, the maximum score for sites was 24 , disease activity was 72 , and pain was 10 (the combined score ranged from 0 to 106). All patients received a 1-year follow-up observation to check for a relapse of the disease. Improvement of symptoms was defined as when the sum of VAS had decreased more than $50 \%$ by the last treatment as compared to the VAS of the first visit. Recurrence was defined as recurrence of symptoms and signs from 2 weeks after the end of treatment.

\section{Statistical analysis}

Statistical analysis was applied to investigate the factors related to successful treatment and the factors related to the recurrence of disease. Baseline data, which had been collected upon the patients' first visit to the hospital, were mainly used to examine. Differences between the symptom-improved group and not-improved group parameters were explored. For the symptom-improved group, the differences between the recurrence group and no-recurrence group parameters were also explored. Independent-sample $t$-test and chi-square test were performed to compare each group via univariate analysis. Statistical significance was accepted at $P<0.05$. All statistical analyses were performed using SPSS ver. 18.0 (SPSS Inc., Chicago, IL, USA).

\section{RESULTS}

In 62 patients diagnosed with OLP, symptoms improved in 50 patients (80.6\%, symptom-improved group), but not in 12 patients (symptom-not-improved group). Twenty-nine of 50 patients had recurrence of OLP (58\%, recurrence group) and 21 
Table 1. Comparison of the baseline data between the symptom-improved group and symptom-not-improved group in OLP patients after intralesional TA injection

\begin{tabular}{|c|c|c|c|}
\hline Variable & Improvement (-) & Improvement (+) & $P$-value \\
\hline No. of patients (\%) & $12(19.4)$ & $50(80.6)$ & - \\
\hline Age $(y r)$ & $58 \pm 13$ & $59 \pm 14$ & 0.823 \\
\hline Male:female & $3: 9$ & $19: 31$ & 0.512 \\
\hline Pain (VAS) & $16.5 \pm 11.8$ & $15.9 \pm 12.4$ & 0.864 \\
\hline OHIP-14 & $35.0 \pm 15.7$ & $42.9 \pm 9.1$ & 0.120 \\
\hline Total severity score & $12.0 \pm 6.3$ & $14.3 \pm 9.9$ & 0.451 \\
\hline Frequency of injection & $3.0 \pm 1.1$ & $4.5 \pm 3.0$ & 0.107 \\
\hline \multicolumn{4}{|l|}{ Accompanying condition } \\
\hline Hypertension & $4(33.3)$ & $24(48)$ & 0.359 \\
\hline Diabetes mellitus & $2(16.7)$ & $13(26)$ & 0.713 \\
\hline Hypothyroidism & $1(8.3)$ & $3(6)$ & 0.999 \\
\hline Dental prosthesis & $3(25)$ & $8(16)$ & 0.432 \\
\hline Allergy & $1(8.3)$ & $1(2)$ & 0.352 \\
\hline Smoking & $2(16.7)$ & $15(30)$ & 0.484 \\
\hline \multicolumn{4}{|l|}{ Involvement site } \\
\hline Lip & $6(50)$ & $6(12)$ & 0.008 \\
\hline Buccal & $10(83.3)$ & $39(78)$ & 0.999 \\
\hline Gingiva & $3(25)$ & $22(44)$ & 0.330 \\
\hline Tongue & $5(41.7)$ & $13(26)$ & 0.305 \\
\hline Floor of mouth & $1(8.3)$ & $1(2)$ & 0.352 \\
\hline Hard palate & 0 & $2(4)$ & 0.999 \\
\hline Soft palate & 0 & $1(2)$ & 0.999 \\
\hline Oropharynx & 0 & 0 & - \\
\hline Multiple sites & 7 (58.3) & $22(44)$ & 0.372 \\
\hline Pathologic type & & & 0.218 \\
\hline Reticular & $11(91.7)$ & $35(70)$ & \\
\hline Plaque & 0 & $2(4)$ & \\
\hline Atrophic & $1(8.3)$ & $2(4)$ & \\
\hline Erosive & 0 & $11(22)$ & \\
\hline
\end{tabular}

Values are presented as number (\%) or mean \pm standard deviation.

OLP, oral lichen planus; TA, triamcinolone acetonide; VAS, visual analogue scale; OHIP-14, Oral Health Impact Profile-14.

of 50 patients did not have recurrence ( $42 \%$, no-recurrence group). In a comparison between the symptom-improved group and the symptom-not-improved group, OLP with lip involvement was the only variable which showed significant difference $(P=0.008)$ (Table 1). Accompanying conditions such as hypertension, diabetes mellitus, hypothyroidism, and dental prosthesis were not significantly different in either group. Other than the site of the lip, any involvement site did not show significant difference. Subjective severity of OLP such as VAS and OHIP-14 scores, and objective severity of OLP such as the total severity score of OLP at baseline, did not show significant differences between groups.

Next, we compared the factors between recurrence group and no-recurrence group. In the comparison between the recurrence group and the no-recurrence group, there was no significantly different in VAS, OHIP-14, the severity score of OLP, accompanying conditions, involvement site, or type of pathology (Table 2).
Table 2. Comparison of baseline data between the no-recurrence group and the recurrence group in OLP patients after intralesional TA injection

\begin{tabular}{|c|c|c|c|}
\hline Variable & Recurrence (-) & Recurrence (+) & $P$-value \\
\hline No. of patients (\%) & $21(42.0)$ & $29(58.0)$ & - \\
\hline Age (yr) & $59 \pm 17$ & $60 \pm 11$ & 0.783 \\
\hline Male:female & $7: 14$ & $12: 17$ & 0.563 \\
\hline Pain (VAS) & $13.0 \pm 11.5$ & $18.0 \pm 12.8$ & 0.162 \\
\hline OHIP-14 & $45.4 \pm 7.9$ & $41.1 \pm 9.6$ & 0.099 \\
\hline Total severity score & $16.3 \pm 12.7$ & $12.7 \pm 7.3$ & 0.255 \\
\hline Frequency of injection & $3.5 \pm 2.9$ & $5.1 \pm 2.9$ & 0.099 \\
\hline \multicolumn{4}{|c|}{ Accompanying condition } \\
\hline Hypertension & $9(42.9)$ & $15(51.7)$ & 0.536 \\
\hline Diabetes mellitus & $5(23.8)$ & $8(27.6)$ & 0.764 \\
\hline Hypothyroidism & $2(9.5)$ & $1(3.4)$ & 0.565 \\
\hline Dental prosthesis & $3(14.3)$ & $5(17.2)$ & 0.999 \\
\hline Allergy & $1(4.8)$ & 0 & 0.420 \\
\hline Smoking & 7 (33.3) & $8(27.6)$ & 0.662 \\
\hline \multicolumn{4}{|l|}{ Involvement site } \\
\hline Lip & $2(9.5)$ & $4(13.8)$ & 0.999 \\
\hline Buccal & $18(85.7)$ & $21(72.4)$ & 0.319 \\
\hline Gingiva & $9(42.9)$ & $13(44.8)$ & 0.890 \\
\hline Tongue & $8(38.1)$ & $5(17.2)$ & 0.097 \\
\hline Floor of mouth & $1(4.8)$ & 0 & 0.420 \\
\hline Hard palate & $2(9.5)$ & 0 & 0.171 \\
\hline Soft palate & $1(4.8)$ & 0 & 0.420 \\
\hline Oropharynx & 0 & 0 & - \\
\hline Multiple sites & $10(47.6)$ & $12(41.4)$ & 0.661 \\
\hline Pathologic type & & & 0.167 \\
\hline Reticular & $18(85.7)$ & 17 (58.6) & \\
\hline Plaque & 0 & $2(6.9)$ & \\
\hline Atrophic & 0 & $2(6.9)$ & \\
\hline Erosive & $3(14.3)$ & $8(27.6)$ & \\
\hline
\end{tabular}

Values are presented as number (\%) or mean \pm standard deviation. OLP, oral lichen planus; TA, triamcinolone acetonide; VAS, visual analogue scale; OHIP-14, Oral Health Impact Profile-14.

\section{DISCUSSION}

In this study, we investigated the factors affecting the efficacy of intralesion corticosteroid injection in OLP patients and tried to find factors related to relapse after treatment. OLP patients with lesions on the lips were less effective in intralesional corticosteroid injection. We did not find any risk factors for recurrence after treatment.

OLP is not a hereditary disease, but it is thought that OLP is closely related to cell-mediated immunity [4]. Cell-mediated immunity and cytokines play an important role in OLP's pathogenesis. This is especially true for cytokines such as tumor necrosis factor- $\alpha$, interleukin- 8 , and interferon- $\gamma$ which cause increased activity of lymphocytes and apoptosis of keratinocytes [16]. Due to the immunological pathogenesis of OLP, OLP has a good response to corticosteroids; therefore, systemic and local corticosteroid therapies are widely used to treat OLP $[10,11]$.

The systemic side effects of topical corticosteroid treatment 
are able to be minimized by administering the corticosteroid treatment effectively, only to the surface of the lesion and the surrounding tissue [17]. Then we selected intralesional TA injection as the therapeutic modality for this study. TA is a synthetic corticosteroid and aqueous, injectable TA material remains longer in the lesion site of OLP owing to its insolubility $[18,19]$. Intralesional TA injection has been known to be a successful treatment of oral submucous fibrosis, temporomandibular joint osteoarthritis, and central giant cell granuloma [20-22]. Treatment for OLP using TA revealed successful results in several studies $[13,23,24]$, and the authors found an $80.6 \%$ cure rate in this study after 6 weeks of intralesional TA injection.

The limitation of any therapeutic trial with regards to OLPwhile evaluating the result of treating OLP-is the lack of standard, objective assessment criteria. Hence, for ensuring objectivity with regards to assessment of the OLP lesion, we utilized the total severity score by Escudier et al. [15] along with the OHIP14 [14], which is a tool that evaluates the subjective quality of life in oral healthcare. Although the results were not found to be statistically significant, the values of the baseline total severity score and OHIP-14 were higher in the symptom-improved group and in the no-recurrence group than in either of the control groups, respectively.

The most common complaint of patients with OLP was oral pain. Oral pain with burning sensation in the oral cavity causes difficulty in oral intake; and this pain makes people go to the hospital to relieve the pain. For these reasons, we thought that using a sum of VAS scores as an index could immediately reflect the oral discomfort of patients. Thus, we considered improvement of symptoms as being when the sum of VAS scores had been found to have decreased more than $50 \%$ by the final treatment.

Meanwhile, it was identified that the number of patients suffering from OLP with lip involvement was higher in the symptom-not-improved group than in the symptom-improved group and the difference was statistically significant. Lips are influenced by OLP earlier than other sites are due to environmental factors such as humidity; temperature; and more frequent, early, and direct exposure to outer stimuli such as foods. As a result, the lips become vulnerable to the frequent stimuli. Thereby, it is thought that for these reasons, OLP with lip involvement was unresponsive to the intralesional TA injection in this study. OLP patients with lesions in the lips should be considered for other therapies other than intralesional injection.

In conclusion, this study suggested that patients suffering from OLP with lesion on the lip might not be effective in treating with intralesional corticosteroid injection.

\section{CONFLICT OF INTEREST}

No potential conflict of interest relevant to this article was reported.

\section{ACKNOWLEDGMENTS}

This research was supported by the Bio \& Medical Technology Development Program of the National Research Foundation (NRF) and funded by the Korean Government (NRF-2015 M3A9E2029189), Republic of Korea.

\section{REFERENCES}

1. Batsakis JG, Cleary KR, Cho KJ. Lichen planus and lichenoid lesions of the oral cavity. Ann Otol Rhinol Laryngol. 1994 Jun;103(6):495-7.

2. Vincent SD, Fotos PG, Baker KA, Williams TP. Oral lichen planus: the clinical, historical, and therapeutic features of 100 cases. Oral Surg Oral Med Oral Pathol. 1990 Aug;70(2):165-71.

3. Colella G, Gritti P, De Luca F, deVito M.The psychopathological aspects of oral lichen planus (OLP). Minerva Stomatol. 1993 Jun;42(6): $265-70$

4. Lozada-Nur F, Miranda C. Oral lichen planus: epidemiology, clinical characteristics, and associated diseases. Semin Cutan Med Surg. 1997 Dec;16(4):273-7.

5. Camisa C, Hamaty FG, Gay JD. Squamous cell carcinoma of the tongue arising in lichen planus: a case report and review of the literature. Cutis. 1998 Oct;62(4):175-8.

6. Markopoulos A, Kayavis I, Paleologoy A, Papanagiotou P, Trigonidis G. Oral lichen planus: a clinical study of 228 cases. Hell Stomatol Chron. 1989 Apr-Jun;33(2):107-11.

7. Lodi G, Scully C, Carrozzo M, Griffiths M, Sugerman PB, Thongprasom K. Current controversies in oral lichen planus: report of an international consensus meeting. Part 2: clinical management and malignant transformation. Oral Surg Oral Med Oral Pathol Oral Radiol Endod. 2005 Aug;100(2):164-78.

8. Femiano F, Cozzolino F, Gaeta GM, De Luca P, Perfetto B, Baroni A. Recent advances on the pathogenesis of oral lichen planus (OLP): the adhesion molecules. Minerva Stomatol. 1999 Apr;48(4):151-9.

9. Toto PD, Nadimi HT. An immunohistochemical study of oral lichen planus. Oral Surg Oral Med Oral Pathol. 1987 Jan;63(1):60-7.

10. Edwards PC, Kelsch R. Oral lichen planus: clinical presentation and management. J Can Dent Assoc. 2002 Sep;68(8):494-9.

11. Vente C, Reich K, Rupprecht R, Neumann C. Erosive mucosal lichen planus: response to topical treatment with tacrolimus. Br J Dermatol. 1999 Feb;140(2):338-42.

12. Lundquist G, Forsgren H, Gajecki M, Emtestam L. Photochemotherapy of oral lichen planus: a controlled study. Oral Surg Oral Med Oral Pathol Oral Radiol Endod. 1995 May;79(5):554-8.

13. Lee YC, Shin SY, Kim SW, Eun YG. Intralesional injection versus mouth rinse of triamcinolone acetonide in oral lichen planus: a randomized controlled study. Otolaryngol Head Neck Surg. 2013 Mar; 148(3):443-9.

14. Slade GD. Derivation and validation of a short-form oral health impact profile. Community Dent Oral Epidemiol. 1997 Aug;25(4):28490.

15. Escudier M,Ahmed N, Shirlaw P, Setterfield J,Tappuni A, Black MM, et al. A scoring system for mucosal disease severity with special reference to oral lichen planus. Br J Dermatol. 2007 Oct;157(4):76570.

16. Mollaoglu N. Oral lichen planus: a review. Br J Oral Maxillofac Surg. 2000 Aug;38(4):370-7.

17. Carbone M, Goss E, Carrozzo M, Castellano S, Conrotto D, Broccoletti R, et al. Systemic and topical corticosteroid treatment of oral lichen planus: a comparative study with long-term follow-up. J Oral 
Pathol Med. 2003 Jul;32(6):323-9.

18. Kumar S, Singh RJ, Reed AM, Lteif AN. Cushing's syndrome after intra-articular and intradermal administration of triamcinolone acetonide in three pediatric patients. Pediatrics. 2004 Jun;113(6):1820-4.

19. JealW, Faulds D. Triamcinolone acetonide: a review of its pharmacological properties and therapeutic efficacy in the management of allergic rhinitis. Drugs. 1997 Feb;53(2):257-80.

20. Lai DR, Chen HR, Lin LM, Huang YL, Tsai CC. Clinical evaluation of different treatment methods for oral submucous fibrosis: a 10year experience with 150 cases. J Oral Pathol Med. 1995 Oct;24(9): 402-6.

21. Kermer C, Millesi W, Watzke IM. Local injection of corticosteroids for central giant cell granuloma: a case report. Int J Oral Maxillofac
Surg. 1994 Dec;23(6 Pt 1):366-8.

22. Haddad IK.Temporomandibular joint osteoarthrosis: histopathological study of the effects of intra-articular injection of triamcinolone acetonide. Saudi Med J. 2000 Jul;21(7):675-9.

23. Xia J, Li C, Hong Y, Yang L, Huang Y, Cheng B. Short-term clinical evaluation of intralesional triamcinolone acetonide injection for ulcerative oral lichen planus. J Oral Pathol Med. 2006 Jul;35(6):32731.

24. Xiong C, Li Q, Lin M, Li X, Meng W,WuY, et al.The efficacy of topical intralesional BCG-PSN injection in the treatment of erosive oral lichen planus: a randomized controlled trial. J Oral Pathol Med. 2009 Aug;38(7):551-8. 